\title{
ANTHONY J. LISSKA, Aquinas's Theory of Perception. An Analytic Reconstruction. Oxford, Oxford University Press, 2016, 353 pp., ISBN: 9780198777908
}

Tomás de Aquino elaboró una sofisticada teoría de la percepción. Según Anthony J. Lisska, la percepción de un objeto de la experiencia no sólo requeriría la información procedente de los llamados sensibles propios y comunes, externos e internos, especialmente la fantasía y la cogitativa, sino también un acto intencional sobrevenido por parte del intelecto agente. Sólo así la razón discursiva podría someter a prueba el inicial significado otorgado a una determinada información sensible, verificando su validez a través de la denominada conversión o reversión al fantasma (conversio ad phantasmata) en cuya elaboración ya no sólo interviene la fantasía o la cogitativa, sino también el propio intelecto agente. Tomás de Aquino habría seguido manteniendo la tesis aristotélica de que el conocimiento intelectual sólo procede de los sentidos, pero completando algunas lagunas que habrían acabado apareciendo en el De Anima. Incluso se puede decir que habría sido un buen empirista, al nivel de Berkeley o Hume, hasta que hacen su entrada la cogitativa o el propio intelecto en este proceso. A este respecto Tomás de Aquino habría establecido una nítida separación entre análisis del objeto o forma percibida, del medio de transmisión de dicha información y del órgano sensible que a su vez la reelabora. Por su parte habría hecho notar la rectificación de la inversión de la imagen sensible que se produce en el proceso perceptivo. O la localización de la percepción en el ventrículo frontal, central y extremo del cerebro, donde a su vez se localizarían el sentido común, la fantasía y la cogitativa, siguiendo a este respecto a Avicena. Pero de igual modo también habría revisado la tesis aristotélica relativa a la necesaria reversión intencional al fantasma, otorgando un mayor énfasis al papel del intelecto agente y de los primeros principios de la razón natural en todo este proceso. Especialmente cuando se contrapongan las tesis aristotélicas a las de algunos materialistas atomistas, como Leucipo y Demócrito, o de los epicúreos, donde el papel del intelecto agente queda totalmente marginado. Por el contrario Tomás de Aquino no habría tenido inconveniente en reconocer el origen innato de los primeros principios de la razón natural, especialmente el de no contradicción. Todo ello también habría hecho que el tomismo fomentara un uso mucho más versátil de la demostración a partir de lo imposible o por reducción al absurdo, o de una interpretación aún más directa del realismo de los universales respecto de los correspondientes singulares, como especialmente ocurre en el proceso de percepción.

De todos modos ahora se reconstruye el proceso perceptivo desde un punto de vista analítico. De ahí que ahora se comparen las propuestas de Tomás de Aquino relativas a la teoría causal de la percepción con las críticas formuladas al empirismo naturalista por Brentano, Read, Gibson, Haldane o Putnam. Se resalta a este respecto el papel desempeñado por la causa como signo formal, que a su vez requiere el concurso del lenguaje ordinario, como también habría hecho notar Tomás de Aquino. Pero de igual modo se comparan las propuestas del aquilate con las teorías de las disposiciones epistemológicas de Kenny, Rely o Geach. O la teleología de la sensación en la medida que se orienta hacía el ejercicio de facultades y saberes cada vez más complejos, separando la percepción directa respecto de la indirecta, la causalidad sensible específica respecto de la modal, el objeto de la sensación y de la cogitativa, las cualidades propias y los sensibles comunes. Se analiza las tres precondiciones y las subsiguientes condiciones de la percepción, como en su caso sucede con el color, la luz y la visión, o con el objeto, el medio y la correspondiente facultad sensible. Por su parte se concibe al sentido común como el sentido interno que reagrupa la información recibida por los sentidos externos, sin atribuirle las funciones más propias de la fantasía, como ocurrió en Avicena. Pero a su vez las revisiones llevadas a cabo por Weinberg, Pasnau, Stump, Shiels o Wolfson a este respecto. Hasta aquí se justifica un realismo directo del conocimiento empírico comparable al de Berkeley o Hume.

Sin embargo Tomás de Aquino se habría separado claramente de las propuestas del empirismo inglés a partir de sus análisis de la estimativa animal y de la cogitativa humana, así como de la memoria. Aparecería entonces la conciencia de lo individual, ya fuera en su forma específica o simplemente concreta, así como el reconocimiento de la correspondiente substancia primera o de las llamadas intenciones no sensibles. Se justifica así un realismo ontológico y una memoria sensible que estaría basada en la aplicación de un principio de individuación, como también ha puesto de manifiesto Jörg Telkamp. De todos modos el aquilate 
habría otorgado a la fantasía un segundo papel de comprobación de las propuestas ahora formuladas por la cogitativa, llevando a cabo una revisión de su anterior realismo tan directo, mediante su comparación con la información recibida por el sentido común y por cada uno de los sentidos, en la medida que se establece entre ellos una relación de imagen y de similitud. En cualquier caso la reversio ad phantasmata se produce una vez que la información sensible ha sido recogida e interpretada en virtud de la fuerza de la cogitativa (vis cogitativa), contando ya con la ayuda del intelecto agente.

Para concluir una reflexión crítica. Lisska inicia su monografía resaltando el contexto naturalista de las propuestas del Aquinate, llevando a cabo un tránsito desde la ontología a la filosofía de la mente. Se trata de propuestas que han despertado un gran interés por parte de la neurociencia, desbordando las pretensiones filosóficas con que fueron formuladas. Algo similar ocurre con el concepto de intencionalidad, que se formuló desde unos presupuestos ontológicos muy precisos, aunque hoy día la filosofía de la mente ha terminado dándole un significado muy distinto. En este sentido lo que se concibió como un acto del ente ha pasado a ser considerado un simple objeto de un proceso mental, sin que el cambio pueda considerarse trivial. Se trata de una observación que, sin duda, señala la distancia existente entre las propuestas del Aquinate y el uso que actualmente se les pretende dar.

CARLOS ORTIZ DE LANDÁZURI Universidad de Navarra

\section{SALVADOR H. MARTÍNEZ, Filosofía de Virgilio de Córdoba. Aristotélico-averroista del siglo XIII, Edición del texto latino y traducción castellana, introducción y notas. León, Universidad de León, 2016, 287 pp., ISBN: 9788497737586}

H. Salvador Martínez, Doctor por la Universidad de Toronto (1972), es profesor emérito de la Universidad de Nueva York, habiendo ocupado la cátedra de Literatura Medieval y Renacentista desde 1976. Ha dedicado diversas monografías a personajes y acontecimientos medievales tan señalados como Alfonso X El Sabio (2016, 2003), Berenguela la Grande (2012), la rebelión de los Burgos (1992), o al «Poema de Almería» (1975), Por su parte, La filosofía de Virgilio de Córdoba, o Virgilio hispano, pretende desentrañar el enigma de un manuscrito medieval que habría sido redescubierto en el siglo XVIII por el copista D. Francisco Xavier de Palomares a partir de otro manuscrito en latín del siglo XIV conservado en la catedral de Toledo, cuya redacción no podría ser posterior a la muerte de Averroes en 1198. Sin embargo el manuscrito original latino anterior del siglo XIII, así como su correspondiente original en árabe no se había podido localizar. En cualquier caso Martínez pretende llevar a cabo una localización de su autor mediante una resolución de las dificultades interpretativas que presenta el análisis textual interno del manuscrito. De este modo se acaba atribuyendo la autoría de la Filosofía de Virgilio de Córdoba a un clérigo mozárabe goliárdico o itinerante del siglo XIII afincado en Toledo de orientación aristotélico-averroísta heterodoxa, amancebado y abanderado de la libertad sexual, adicto a la nigromancia o magia negra, que escribe en un latín muy vulgar y que presenta pocas o ninguna señal de saber árabe. Se pretende así retrotraer la presencia a nivel popular del averroísmo latino en España al siglo XIII, ejerciendo una fuerte influencia muy directa en las obras de los arciprestes de Hita y de Talavera, entre otros, así como en toda Europa.

Además, en este estudio también se señalan otras apropiaciones indebidas de la figura de Virgilio, el autor de la Eneida. Por ejemplo, la de Virgilio Maro Grammaticus, o el pseudo Virgilio de Toulouse del siglo VII, aunque ninguna de sus obras pudiera ser anterior al siglo XI. También se describen las pintorescas reacciones de Marcelino Menéndez Pelayo o de F. Delpech ante sus bernardinas disparatadas o su picardía nigromante, aunque situándolas en el siglo XIV. Sin embargo, a pesar de todo, Martínez cree encontrar en sus escritos una valiosa información sobre el estado del sistema educativo medieval del trivium y quadrivium, tanto en Toledo como en la Córdoba del siglo XIII. Se resalta así la importancia ahora otorgada por el 